\title{
EL REY ANTE SUS SÚBDITOS. PRESENCIA DE FERNANDO VII EN EL ESPACIO PÚBLICO
}

\section{THE KING BEFORE HIS SUBJECTS. THE PRESENCE OF FERNANDO VII IN THE PUBLIC SPACE}

\author{
Emilio La Parra López \\ Universidad de Alicante
}

SUMARIO: INTRODUCCIÓN.- I. LA IMAGEN DEL REY EN EL ESPACIO PRIVADO.- II. NACIMIENTO DE LA POLÍTICA.- III. RESTAURACIÓN DEL ABSOLUTISMO.- IV. EL JURAMENTO DE LA CONSTITUCIÓN POR EL REY.- V. EL TRIUNFO DE FERNANDO VII.- VI. EL REY EN CUBA.- VII.- CONSIDERACIÓN FINAL.- VIII. ILUSTRACIONES

Resumen: Este texto se centra en el significado político de los monumentos en honor a Fernando VII proyectados para ser exhibidos de forma permanente en el espacio público, en las calles y plazas de las ciudades de la monarquía hispana. Todos ellos se idearon en vida del monarca. Salvo contada excepciones, a su muerte fueron destruidos o apartados del lugar para el que habian sido concebidos. El rey concedió especial importancia a esta forma de presentar su imagen, que consideró un medio para consolidar su modelo de monarquía despótica y preservar su recuerdo.

\begin{abstract}
This text focuses on the political meaning of the monuments in honor of Ferdinand VII projected to be permanently displayed in the public space, in the streets and squares of the cities of the Hispanic monarchy. All of them were designed in the life of the monarch. With few exceptions, at their death they were destroyed or removed from the place for which they were conceived. The king attached particular importance to this way of presenting his image, which he considered a means to consolidate his model of despotic monarchy and preserve his memory.
\end{abstract}

Palabras clave: Fernando VII, monumentos, memoria, política.

Key Words: Ferdinand VII, monuments, memory, politic. 


\section{INTRODUCCIÓN}

Se pretende ofrecer en estas páginas algunos datos, necesariamente provisionales, acerca de las esculturas de Fernando VII emplazadas en lugares públicos. ${ }^{1}$ Tales representaciones, de acuerdo con el estado actual de nuestro conocimiento, solo se proyectaron durante la vida del rey: la primera data de 1809 y las últimas de los años finales de su reinado. ${ }^{2}$ Casi todas estas estatuas han sido destruidas y las que no han corrido esta suerte no permanecen en la actualidad en el espacio para el que fueron concebidas.

Estas obras tuvieron un carácter monumental, es decir, se trata -según el Diccionario de la Real Academia de la Lengua- de realizaciones públicas y patentes en memoria de la persona representada. Su finalidad fue triple: homenajear al rey, declarándole lealtad y sumisión; hacerlo presente en todo el territorio de la monarquía, el europeo y el de ultramar, y perpetuar su recuerdo. ${ }^{3}$ Como se intentará demostrar en estas páginas, los dos primeros objetivos fueron en realidad los que más importaron al monarca.

No tomaré en consideración los monumentos efimeros con que las ciudades homenajearon al monarca en ocasiones señaladas, las cuales no fueron escasas durante este reinado, como no lo habian sido en los anteriores. ${ }^{4}$ Tampoco trataré de las estatuas de Fernando VII ubicadas en lugares privados, como el palacio real, las mansiones de la nobleza, o los edificios de organismos oficiales, incluido el interior del Museo del Prado -creado durante el reinado de este monarca-, donde podían ser visitados por muchas personas, pero siempre escogidas. Me centraré en las esculturas del rey destinadas a perdurar y a ser mostradas en el espacio público, en calles y plazas; esto es, aquellos monumentos dedicados al rey pensados para su exhibición en un lugar de propiedad pública, por donde se pudiera transitar libremente; más aún, por donde se suponía que lo harian gentes de todas las clases. Lo que pretendo, en suma, es una aproximación a un fenómeno, la representación de Fernando VII, destinado a crear una determinada

1 Este texto se ha realizado en el marco del Proyecto de I+D+I financiado por el Ministerio de Economia: "Las monarquías en Europa meridional (siglos XIX y XX). Culturas y prácticas de la realeza" (HAR2016-75954-P).

2 Según mis noticias, solo se ha erigido una escultura en honor de Fernando VII después de su fallecimiento (29 de septiembre de 1833). Se trata de un busto de la cabeza del rey colocado sobre un pedestal, que se ubicó en 2001 en una plaza del municipio de Navas del Rey (Madrid), con la siguiente inscripción: "En agradecimiento a Fernando VII que por Real Carta de 22 de abril de 1819 concedió a Navas del Rey el privilegio de villazgo." Debido a las protestas de vecinos y foráneos, el Ayuntamiento decidió en 2004 retirar la estatua. El decreto de alcaldía que así lo decidió la justificó porque "fue el rey más nefasto que España ha tenido y uno de los más violentos y represores del pueblo." (El País, 8-9-2004)

3 Sobre el significado del monumento como elemento de la memoria colectiva, vid. Jacques Le Goff, El orden de la memoria. El tiempo como imaginario, Paidós, Barcelona, 1991, pp. 227-228; Johannes Sträter, "El recuerdo histórico y la construcción de significados politicos. El monumento al emperador Guillermo en la montaña de Kyffhäuser", Historia y Política, 1, 1991, pp. 83-106 e Ignacio Peiró Martín, En los altares de la patria. La construcción de la cultura nacional española, Akal, Madrid, 2017, cap. III (esta obra contiene abundantes referencias bibliográficas).

4 El recurso al arte efímero para homenajear a Fernando VII alcanzó una dimensión considerable. Véase Ester Alba Pagán, La pintura y los pintores valencianos en la Guerra de la Independencia y el reinado de Fernando VII (1808-1833), Universitat de València, València, 2004; Ana Rosa Domínguez Santamaria, "Madrid, escenario propagandístico de un rey absoluto," Aportes, $\mathrm{n}^{\circ} 41,1999$, pp. 47-64. 
idea de la monarquía encarnada por ese rey. En consecuencia, mis consideraciones se limitarán al significado político de esos monumentos públicos. Prescindiré, entre otros factores, de sus autores y de su valor estético, y seguiré un criterio cronológico, acorde con los cambios de sistema político.

El monumento público no religioso es propio del tiempo político. ${ }^{5}$ Surge cuando la política deja de estar reducida al ámbito privado de la corte y de una forma u otra pasa a ser una actividad susceptible de ser desempeñada por la generalidad de la población. Lugar privilegiado de la política es la ciudad, de ahí el interés del poder por ocupar sus calles de la manera más variada. Una de las formas más respetables y perceptibles es el monumento en homenaje a las personas juzgadas merecedoras de reconocimiento. Coincidiendo con el nacimiento de la politica moderna, desde finales del siglo XVIII se erigieron en ciudades europeas y americanas estatuas a hombres distinguidos en la construcción de la nación y de la propia ciudad. Con ello se pretendió configurar "el paisaje de la memoria oficial". 6 Este proceso alcanzó su apogeo en España a partir de 1875, en la época de la Restauración, pero no fueron escasas las actuaciones en esta dirección durante los decenios anteriores.

A pesar de su concepto arcaico de la monarquía y del rechazo de todo tipo de participación política, ${ }^{7}$ y con independencia de su obra de gobierno, Fernando VII captó los aires del nuevo tiempo, de manera que acogió con agrado cuantas iniciativas le llegaron para tributarle homenaje y perpetuar su memoria, y aun él mismo se ocupó de potenciarlas.

\section{LA IMAGEN DEL REY EN EL ESPACIO PRIVADO}

Durante el Antiguo Régimen se homenajeó con frecuencia en público a los reyes mediante arquitecturas efimeras, en las que aparecian sus retratos y múltiples alegorias de sus virtudes personales. A través de este recurso, el pueblo expresaba lealtad a su soberano en momentos señalados, como el de su proclamación, su entrada en la capital del reino para simbolizar la imposición de su autoridad suprema, su matrimonio, etc. También era usual recibir al monarca con ese tipo de representaciones efimeras en las ciudades que visitaba. Sin embargo, rara vez se erigieron estatuas de los reyes en los espacios públicos urbanos. Según Carlos Serrano, no se consideró necesario. Por una parte, porque "el mundo clerical y eclesiástico, con sus propias ceremonias y lugares de culto, con sus arquitecturas efimeras sobre todo, captaba en lo fundamental la

5 Maurice Agulhon, Marianne au combat: l'imagerie et la symbolique Républicaines de 1789 à 1880, Flammarion, Paris, 1979, y del mismo autor : Politica, imágenes y sociabilidades. De 1789 a 1989, Publicaciones de la Universidad de Zaragoza, Zaragoza, 2016, pp. 119-162.

6 Ignacio Peiró, En los altares de la patria. La construcción de la cultura nacional española, op. cit., pp. 194-195.

$7 \mathrm{Su}$ concepto de monarquía se fundaba en la doctrina del absolutismo racionalista de inspiración iusnaturalista, según la cual la soberanía real, entendida como potestas absoluta, era un atributo exclusivo del monarca, que le facultaba para intervenir en todos los asuntos de su reino, al que consideraba patrimonio de su Casa. Asimismo participó de la concepción teocrática y providencialista de la monarquía expuesta por los teóricos reaccionarios frente a los revolucionarios franceses. (Emilio La Parra, Fernando VII. Un rey deseado y detestado, Tusquets, Barcelona, 2018, pp. 279-280) 
representación simbólica del poder y de su proyección pública." Por otra, porque los propios reyes no mostraron interés en ofrecer su imagen a la contemplación permanente de sus súbditos, pues daban por supuesta su fidelidad (la exigía el mantenimiento del inmutable orden natural creado por Dios) y, además, esta era encauzada por las representaciones religiosas. ${ }^{8}$ Todo ello no significa ausencia del rey en el espacio público. El escudo real aparecía en las fachadas de muchos edificios, y proliferaban las alegorias de la monarquía y las inscripciones con el nombre del rey en los más diversos lugares (cuarteles, templos, fuentes...). ${ }^{9}$

Los reyes encargaron estatuas de sí mismos, o permitieron que otros lo hicieran, pero su destino no fue el espacio público, sino la corte. En el tiempo pre-político, la corte era el núcleo del poder, y en consecuencia, el lugar idóneo donde mostrarse el soberano con toda su majestad. Puesto que la opinión pública no contaba, sino el orden cortesano, la "sociedad de corte", el rey se exhibía en ella para manifestar la potestas absoluta, atributo exclusivo suyo, ante la nobleza, la jerarquía eclesiástica y los representantes diplomáticos de otros reinos. ${ }^{10}$ No obstante, en ciertos casos y por distintas razones, en el siglo XVIII se traspasó el ámbito cortesano y se colocaron esculturas de los reyes en lugares públicos. En 1719 se levantaron en Valencia dos grandes columnas en el Llano del Real, junto al palacio ocupado históricamente por los reyes, una de las cuales estaba rematada por los bustos de Felipe V y de su esposa María Luisa de Saboya. ${ }^{11}$ Se pretendia con ello hacer patente la soberanía de ese monarca sobre el antiguo reino de Valencia tras la resistencia ofrecida por algunos sectores de la población durante la Guerra de Sucesión. Para dar a entender que gozaba del favor real, el Consulado de Burgos erigió en 1784 una estatua a Carlos III en la plaza mayor de aquella ciudad. ${ }^{12}$

Como es lógico, donde más abundaron las estatuas de los reyes exhibidas ante el público fue en los territorios de Ultramar, porque era preciso revelar su presencia en esos reinos tan lejanos a los que nunca se desplazó en persona ningún soberano. Desde finales del siglo XVIII, la representación más célebre, tanto por su calidad estética, como por su significado, fue la estatua ecuestre de Carlos IV colocada en la plaza principal de la ciudad de México en 1796, el día del aniversario de la reina María Luisa, realizada inicialmente en madera y en 1803 fundida en bronce, obra de Manuel Tolsá. ${ }^{13}$ Coincidiendo con la inauguración de

8 Carlos Serrano, El nacimiento de Carmen. Símbolos, mitos y nación, Taurus, Madrid, 1999, pp. 189-190.

9 Es muy frecuente hallar en fuentes y otras ornamentaciones públicas, así como en los palacios reales, un león, emblema de la monarquía, y la figura de Hércules, héroe virtuoso, simbolo de la fuerza, considerado por los Austrias el mítico fundador de la monarquía hispana. Goya recogió esta idea en La familia de Carlos IV (Manuel Mena, Goya. La familia de Carlos IV, Museo del Prado, Madrid, 2002).

10 Roger Chartier, "Préface" a Norbert Elias, La société de Cour, Flammarion, Paris, 1985.

11 Elena De las Heras Esteban, La escultura pública en Valencia. Estudio y catálogo, Tesis doctoral, Universidad de Valencia, 2003, p. 33.

12 Pierre Géal, (2007), "Un siglo de monumentos a la Guerra de la Independencia", en Christian Demange et al., Sombras de mayo. Mitos y memorias de la Guerra de la Independencia en España (1808-1908), Casa de Velázquez, Madrid, 2007, p. 136.

13 Conocida como "El caballito", en la actualidad está ubicada en el Palacio de la Minería de esa ciudad, obra asimismo de Tolsá, símbolo de la riqueza proporcionada por México a la monarquía hispana (Joaquín Berchez, Tolsá en la arquitectura española de su tiempo, en VV.AA, Tolsá, 
esta estatua, el gobernador de Filipinas encargó otra del mismo rey, en esta ocasión de cuerpo entero de pie, al escultor de cámara Juan Adán. Hasta 1824 no se colocó esta escultura en el lugar para el que fue destinada, la plaza mayor de Manila, centro político del archipiélago, donde estaban ubicados el ayuntamiento, el palacio del gobernador y la catedral. La estatua ha perdurado en el mismo lugar (hoy plaza de Roma), quizá porque la inscripción colocada a principios del s. XIX indica que se erigió en gratitud a Carlos IV por llevar a ese territorio la vacuna contra la viruela gracias a la expedición de Balmis. ${ }^{14}$ Otros monumentos a los reyes en el tiempo de Carlos IV fueron la estatua ecuestre de Carlos III en Santiago de los Caballeros (Guatemala), realizada en 1789, hoy desaparecida, y la dedicada al mismo monarca en el Paseo de Extramuros de La Habana (1803), obra de Cosme Velázquez, actualmente en el Palacio de los Capitanes Generales, museo de la ciudad de La Habana. ${ }^{15}$

\section{NACIMIENTO DE LA POLÍTICA}

A partir de 1808, con el inicio de la politica moderna en España, ${ }^{16}$ se experimentó un cambio muy apreciable, producto de dos factores, que unas veces se alimentaron mutuamente y otras se contrarrestaron: por una parte, el deseo popular, encauzado por los liberales, de homenajear y perpetuar la memoria de los héroes de la patria y los grandes acontecimientos políticos y bélicos de la nación; por otra, la firme determinación de Fernando VII desde 1814 de conceder preeminencia a su persona sobre todo lo anterior.

Durante los años de la guerra de la Independencia se idearon varios proyectos de monumentos, concebidos -mantiene Pierre Géal, que ha contabilizado 21 de ellos presentados a las Cortes de Cádiz- como un homenaje de la nación a sí misma. Los temas fueron diversos: Pedro Velarde, José Palafox, Wellington, las víctimas del Dos de Mayo, el heroísmo de los zaragozanos, ciertas victorias militares, la reunión y obra de Cortes, la proclamación de la Constitución, la abolición de los señoríos y de la Inquisición, etc. En todos los casos, la figura Fernando VII quedaba en segundo plano. Solo dos proyectos se refirieron expresamente a él. Ambos contemplaban la erección de una estatua del rey, una en Valencia, y la otra -ecuestre- en la plaza Mayor de Madrid (esta última se presentó en la sesión parlamentaria del 24 de noviembre de 1813.) ${ }^{17} \mathrm{El}$

Gimeno, Fabregat. Trayectoria artística en España. Siglo XVIII, Generalitat Valenciana, Valencia, 1989, pp. 54-56).

14 Pedro Luengo Gutiérrez, "El monumento a Carlos IV en Manila, obra de Juan Adán", Academia, $\mathrm{n}^{\circ}$. 108-109, pp. 65-78, demuestra que la idea de la estatua surgió en 1796, antes pues de la llegada a Filipinas de la expedición de Balmis, que tuvo lugar en 1805, quizá por emulación de la ecuestre de México y en agradecimiento al rey por la desvinculación de Filipinas del control del Virreinato de Nueva España y la creación de la Compañía de Filipinas, lo que convertía a Manila en el centro del comercio con Oriente.

15 Rodrigo Gutiérrez Viñuales, Monumento conmemorativo y espacio público en Iberoamérica, Cátedra, Madrid, 2004, pp. 170-174.

16 Sobre el comienzo de la política en España, véase el monográfico: El nacimiento de la politica moderna en España, n 35-1, 2005, de Mélanges de la Casa de Velázquez.

17 Pierre Géal, “Un siglo de monumentos a la Guerra de la Independencia”, op. cit., pp. 137-139. 
monumento de Madrid no se llegó a realizar. El de Valencia sí, aunque no duró mucho.

E1 23 de mayo de 1809 se colocó una estatua de Fernando VII en la plaza de la Virgen de Valencia. Era un busto del rey "a la griega" alzado sobre una columna. La mandó realizar el capitán general en conmemoración del levantamiento de la ciudad contra Napoleón, ocurrido el mismo día y mes del año anterior (Valencia fue una de las primeras ciudades españolas en declarar la guerra al francés en nombre de Fernando VII). Con motivo de su inauguración se acuñaron medallas con esta inscripción: "Valencia ratificó su juramento sellado con su sangre", que fueron distribuidas entre el público. ${ }^{18}$ Se pretendia dejar constancia de la fidelidad de la ciudad. La estatua era asimismo un modo de "hacer presente" al rey ausente. ${ }^{19}$ Recordaba a los valencianos que tenían el deber de seguir luchando para devolver al trono a su soberano, quien no estaba en ese momento entre ellos porque era víctima del tirano exterior, que con engaños lo había alejado de España y lo mantenía cautivo en Francia. De esto trató una oda, titulada A la estatua erigida por la ciudad de Valencia en honor de su augusto soberano Fernando VII, que fue impresa para facilitar su difusión. ${ }^{20}$ En ella se dice que este monumento tiene la finalidad de conmemorar el acontecimiento heroico del levantamiento de Valencia contra Napoleón: "Mirad cuál se eleva / con magestad y pompa / un monumento augusto / que hasta la más remota / posteridad recuerde / hazañas tan gloriosas." La estatua es testimonio de la fe y amor que juró Valencia al trono, y específicamente a Fernando, porque cumple la misma función que si el rey estuviera presente: "Adorada la Estatua / cual si FERNANDO [sic] fuera." Sirve para que "los siglos venideros" aprendan lecciones de lealtad, celo, amor, entusiasmo, valor y denuedo. Poco duró este monumento, pues los propios valencianos lo derribaron, desconozco por qué motivo, antes de que Suchet tomara la ciudad a principios de enero de $1812 .{ }^{21}$

\section{RESTAURACIÓN DEL ABSOLUTISMO}

El 25 de marzo de 1814, día siguiente al de la entrada de Fernando VII en suelo español a su vuelta de Valençay, el general Francisco Copons envió desde Gerona una exposición a las Cortes solicitando que "se decretase un monumento público para perpetuar el memorable día del 24 del corriente en que he tenido la dicha de recibir a nuestro Rey..." El diputado Plandolit recogió la idea y en la

18 A este hecho se hizo alusión en las Cortes de Cádiz, en la sesión pública del 31 de mayo de 1811 (Diario de Sesiones de las Cortes Generales y Extraordinarias, J. García, Madrid, 1870, p. $1155)$.

19 Richard Hocquellet, La revolución, la politica moderna y el individuo: miradas sobre el proceso revolucionario en España (1808-1835), Prensas Universitarias de Zaragoza, Zaragoza, 2011 , p. 99. El mismo objetivo se persiguió con el retrato del rey al óleo Fernando VII con el hábito de la Orden de Santiago, pintado por Vicente López en Valencia en 1808 (véase José Luis Díez, "Nada sin Fernando. La exaltación del Rey Deseado en la pintura cortesana (1808-1823)", en Goya en tiempo de guerra, Museo del Prado, Madrid, 2008, p. 102.

20 La oda fue publicada en Valencia por Salvador Fauli, 1809.

21 María Francisca Olmedo de Cerdá, Callejeando por Valencia, Carena eds., Valencia, 2003, p. 135 . 
sesión extraordinaria de Cortes del 28 de marzo propuso que se levantase una pirámide en el punto propuesto por Copons: la margen derecha del Fluvià, frente a la localidad de Bàscara, donde el rey abandonó el territorio dominado por el ejército francés. La proposición se pasó a una comisión del parlamento, que acordó la expedición de un decreto favorable a la erección del monumento. Su diseño debería presentarse a la Academia de San Fernando, y a la de la Historia se encargaría la inscripción correspondiente. El dictamen fue aprobado en la sesión pública del 20 de abril siguiente. El decreto salió con fecha del 23, pero el monumento no llegó a ejecutarse. ${ }^{22}$ Téngase en cuenta, por lo demás, que aquellas Cortes fueron abruptamente clausuradas el 10 de mayo, en el marco del golpe de Estado perpetrado por el propio Fernando VII.

Parecida suerte corrió el monumento proyectado por el capitán general de Valencia Francisco Javier Elío, en este caso quizá por falta de tiempo, pues en 1820 Elío fue encarcelado y procesado por los liberales. Consistió en levantar una estatua colosal del rey, de cuerpo entero, en el centro del paseo de Santo Domingo, junto al edificio neoclásico de la Aduana, lugar privilegiado de la ciudad de Valencia. La estatua no llegó a ser esculpida, pero con el dinero recaudado se creó el excelente jardín destinado a servir de marco a la escultura real. ${ }^{23}$

Solo en dos lugares llegó a materializarse en estos años el homenaje a Fernando VII. Uno fue Alcalá de Henares, aunque el protagonismo recayó en El Empecinado. En diciembre de 1814, esta ciudad acordó levantar una pirámide en honor del distinguido guerrillero, vencedor en ese lugar de los franceses. El rey dio su visto bueno, pero exigió que en la inscripción se mencionase su nombre. Quedó como sigue: "La Ciudad de Alcalá de Henares dedica este monumento a la memoria de las Valientes tropas de S. M. el Sr. Fernando Séptimo mandadas por D. Juan Martín el Empecinado, Mariscal de Campo de los Reales Ejércitos, en reconocimiento de haber salvado a sus moradores del saqueo y muerte, arrollando y batiendo a los franceses en la mañana del 22 de Mayo de 1813 en que en doble número atacaron por este puente." La pirámide fue destruida por el realismo extremista en 1823, cuando el monarca consideró al Empecinado enemigo suyo, muy peligroso (dos años después, el héroe guerrillero murió en la horca por orden real). ${ }^{24}$

El otro monumento a Fernando VII ejecutado en este tiempo está en Madrid y es de los escasísimos que ha perdurado hasta nuestros dias, quizá porque no representa la figura del rey; también por su utilidad, pues se trata de una fuente (figura 1). Está emplazado en la confluencia de la calle Arganzuela con la de Toledo, en el barrio de La Latina. Consiste en una pilastra de planta cuadrangular, en cuya cara principal consta la siguiente inscripción: "A Fernando VII, el Deseado. El Ayuntamiento del heroico pueblo de Madrid. Corregidor, el conde de Motezuma (sic). Año de MDCCCXV". Bajo esta placa, un grupo escultórico formado por un oso y un grifo alude al antiguo escudo heráldico de Madrid. A otros lados de la pilastra figuran blasones históricos de la villa con el oso y el madroño. Corona el monumento un cubo de piedra con las siete estrellas

22 AHN, Estado, 3566, expte. 73.

23 María Francisca Olmedo de Cerdá, Callejeando por Valencia, op. cit. p. 135; Elena De las Heras Esteban, La escultura pública en Valencia. Estudio y catálogo, op. cit., p. 42.

24 Pierre Géal, “Un siglo de monumentos a la Guerra de la Independencia”, op. cit., pp. 142-143. 
del escudo de Madrid, rematado con la escultura de un león erguido sobre dos hemisferios terrestres, simbolizando los dominios de la monarquía española en Europa y Ultramar. El monumento, inaugurado en 1815, como reza la placa, fue iniciativa del conde de Moctezuma, corregidor de Madrid, para conmemorar el regreso del monarca a la capital tras su "cautiverio" en Valençay. Si nos fiamos de los juicios de los cronistas de la villa, nunca ha despertado la admiración de la población. El más conocido de ellos, Mesonero Romanos, lo calificó, tal vez con excesiva severidad, de "desdichada fuente", monumento "fúnebre del buen gusto." 25

Durante el sexenio 1814-1819 fueron muchos los homenajes al rey recuperado y "deseado", pero estos se realizaron fundamentalmente al estilo antiguo, mediante ceremonias religiosas en el espacio cerrado de los templos, de manera que lo consignado arriba viene a ser excepción.

\section{EL JURAMENTO DE LA CONSTITUCIÓN POR EL REY}

Los proyectos de monumentos al rey que habian sido presentados a las Cortes de Cádiz cayeron en el olvido durante el Trienio Liberal. El dato es llamativo, pues como es sabido, a partir de 1820 se retomaron muchos asuntos planteados en el anterior tiempo constitucional. Según Pierre Géal, en el nuevo escenario político el interés se centró en homenajear a las víctimas del absolutismo, en particular a los generales Lacy y Díaz Porlier, y en rememorar personajes históricos tomados como referentes por los liberales (los Comuneros de Castilla y el Justicia Mayor de Aragón, Lanuza.) ${ }^{26}$ Los proyectos para homenajear en el espacio público al rey fueron muy escasos y ninguno de ellos se materializó.

El 10 de julio, segundo día de andadura de las nuevas Cortes, los diputados Vargas Ponce y Marcial López presentaron sendas proposiciones, cuyo sentido explicaron unos días después. El primero sugirió una serie de actuaciones, entre otras la elevación de dos columnas jónicas en la plaza de las Cortes, como demostración "dirigida al público (...) para perpetuar...la fausta memoria del solemne juramento del Rey" de la Constitución, dia "quizá el más fausto que presenta la historia nacional; y sin género de duda, el mayor y más glorioso que ha gozado el Rey." El homenaje, por consiguiente, no iba destinado directamente a la persona del monarca, sino a su función simbólica como suprema encarnación del nuevo Estado constitucional, cuyo establecimiento quedaba respaldado por el juramento real. En sentido muy similar cabe entender la propuesta de Marcial López: "pido que se erija un monumento al Rey, porque contribuyó a salvar, o por mejor decir, porque salvó la patria." El monumento consistiría en una estatua "coronado de una corona cívica." No explicitó el

25 Ramón de Mesonero Romanos, El antiguo Madrid. Paseo histórico-anecdótico por las calles y casas de esta villa, F. Mellado, Madrid, 1861, p. 177 (ed. digital en Biblioteca Virtual Miguel de Cervantes).

26 Pierre Géal, “Un siglo de monumentos a la Guerra de la Independencia.”, op. cit., p. 141. 
diputado aragonés en qué consistió esa "salvación" de la patria, pero dado el contexto es evidente su relación con la jura de la Constitución. ${ }^{27}$

Las Cortes recibieron con agrado las dos proposiciones y, como era habitual, encargó a la Academia de San Fernando la convocatoria de un concurso para hacerlas realidad. Esta aprobó el proyecto presentado por el arquitecto Custodio Teodoro Moreno, discípulo de Juan de Villanueva, consistente en la construcción en la subida al Retiro por el lado del convento de S. Jerónimo de un edificio con funciones docentes, que sugirió fuera denominado Liceo Nacional o Español, a cuya entrada se colocaría una estatua de Fernando VII bajo un templete jónico. Habría también un arco triunfal en la fachada principal lleno de esculturas y alegorias, y en su ático esta leyenda: "Es de Fernando digno monumento/ y de española gloria fundamento." 28

En el mismo mes de julio de 1820, Manuel Cesáreo del Castillo, párroco de Las Rebolledas (Burgos), presentó a la Academia de la Historia, de la que era correspondiente, la propuesta de erección de una estatua del rey con motivo de la "restauración de la Monarquía española moderada," como era definida en el artículo 14 de la Constitución de 1812. El cura propuso dos inscripciones para el pedestal de la estatua. La una rezaba: "A Fernando VII, Rey poderoso de las Españas, el próvido, pío, feliz, Augusto Padre de la Patria, el Pueblo reintegrado en sus derechos en las Cortes de la heroica villa de Madrid, de IX de julio de MDCCCXX." Y la otra: "A Fernando VII, Rey poderoso de las Españas, el próvido, pio, feliz, Augusto, Padre de la Patria, el pueblo, restituido al sagrado derecho de libertad civil, y admitido al gobierno de su grande Monarquía en las Cortes de la heroica villa de Madrid, de 9 de julio de 1820."29

Ninguno de los proyectos mencionados se llevó a la práctica. Evidentemente, el tiempo no era propicio para ello. A pesar de las esperanzas puestas por los liberales en Fernando VII -muchos creyeron que tras el juramento de la Constitución sería por fin rey constitucional- no tardó en llegar el desengaño. Enseguida circularon rumores sobre el apoyo del monarca a los movimientos conspirativos absolutistas, y paulatinamente se hicieron más patentes los intentos del rey por obstaculizar la obra de las Cortes y evitar la consolidación del régimen constitucional.

\section{EL TRIUNFO DE FERNANDO VII}

En 1823 se impuso Fernando VII al constitucionalismo gracias a la ayuda militar y diplomática europea. A partir de entonces ejerció su autoridad mediante la fuerza y la represión. Su control sobre todos los asuntos públicos fue completo, pero vivió en continuo desasosiego, atenazado por el temor a las acciones

27 Diario de las actas y discusiones de las Cortes. Legislatura de los años 1820 y 1821, Imprenta de Diego García y Campoy, Madrid,1820, tomo I, pp. 44 y 111-114 (sesiones del 10 y del 16 de julio de 1820).

28 Enrique Pardo Canalís, "Proyectos de monumentos conmemorativos en Madrid de 1820 a 1836”, Archivo Español de Arte, n 103, 1953.

29 Real Academia de la Historia, CAM/9/7961/004, texto digitalizado en la Biblioteca Virtual Miguel de Cervantes: http://www.cervantesvirtual.com/obra-visor/carta-de-remision-de-dosmodelos-de-inscripcion-para-el-pedestal-de-una-estatua-que-ha-de-erigirse-en-honor-de-

fernando-vii/html/de1dc200-2dc6-11e2-b417-000475f5bda5.html 
emprendidas desde el exterior por los liberales, y a los brotes de descontento interior originados por estos, de una parte, y por los ultra realistas, de otra. Por este motivo, en esta última etapa de su reinado fue asunto prioritario para Fernando VII reafirmar la fidelidad de sus súbditos. Además de los mecanismos represivos, muy abundantes y de variada naturaleza, se sirvió de los recursos propagandísticos disponibles en la época, a alguno de los cuales imprimió un sesgo moderno, cual fue el caso de los viajes por el territorio nacional, perfectamente programados para recibir el homenaje de fidelidad de sus súbditos. ${ }^{30}$ Con esta misma finalidad, el rey concedió un lugar destacado a la presentación pública de su figura.

Los monumentos levantados con anterioridad a 1824 habian pretendido ensalzar al rey, primero porque era referente para mantener la lucha contra Napoleón, luego porque en él se personificó la victoria, y más tarde porque se le presentó como símbolo de la construcción del sistema constitucional. A partir de la fecha mencionada su función fue claramente propagandística: asegurar la fidelidad de sus súbditos para garantizar el sistema político despótico establecido tras el derrocamiento del constitucionalismo. A pesar de todo, tampoco en este tiempo fueron abundantes los monumentos que llegaron a ser ejecutados probablemente porque se careció de fondos económicos para empresas de esta naturaleza-, pero si tenemos en cuenta que constituyeron novedad como forma de hacer política, su número es significativo. La mayoría fue resultado de la iniciativa privada. Ahora bien, como quiera que todo lo que tuviera alguna repercusión pública era controlado por el rey, porque siempre se requería su permiso, podemos afirmar que directa o indirectamente Fernando VII intervino en todos los casos. Especialmente patente fue su influencia en las inscripciones, que invariablemente aludieron a la fidelidad del pueblo y al acatamiento de la autoridad real.

Ejemplo palmario del intervencionismo directo de Fernando VII fue el proyecto del Canal de Aragón. Su protector, el marqués de Lazán, solicitó autorización real en 1828 para levantar una estatua en honor de Ramón Pignatelli, su antecesor en el cargo. El ministro Calomarde respondió que en lugar de Pignatelli se representara al rey y a la reina María Josefa Amalia para perpetuar su estancia en Zaragoza. Por supuesto, la orden fue asumida. Se encargó la obra a José Álvarez Bouquel, hijo del famoso escultor Álvarez Cubero. Tras el fallecimiento de la reina en mayo del año siguiente, el proyecto quedó paralizado. Se retomó más tarde, con la intención de que acompañara a la estatua del rey la de su nueva esposa, María Cristina, pero Fernando VII insistió en que se mantuviera la de la difunta María Josefa Amalia. Al morir en 1830 el escultor Álvarez Bouquel, el proyecto fue definitivamente abandonado. En 1859, un cuarto de siglo después de la desaparición de Fernando VII, se erigió por fin la estatua a Pignatelli, obra de Antonio Palao. ${ }^{31}$

Siguiendo un orden cronológico, que dada la dificultad en precisar cuándo nació cada una de las iniciativas ha de ser aproximado, el primero de los

30 Sobre el significado político de los viajes del rey, vid. Emilio La Parra, Fernando VII. Un rey deseado y detestado, op. cit., especialmente pp. 554-568.

31 Enrique Pardo Canalís, “José Álvarez Bouquel, una esperanza malograda”, Goya, n 78, 1967, p. 373. 
monumentos a Fernando VII levantados después del derrocamiento por segunda vez del sistema constitucional fue el proyectado en Murcia, impulsado en 1824 por el corregidor de la ciudad, Rafael Garfias. Su intención la expuso con claridad meridiana en el momento de su inauguración: "Deseoso de dar un testimonio público de mi amor al R. N. S. D. Fernando VII (...) me propuse perpetuar la memoria de tan amado y respetado monarca en la plaza real de esta ciudad, en que se colocase su real estatua..."32 Ubicada en el centro de la ciudad, en la Glorieta, fue inaugurada el 2 de febrero de 1831 con parada de tropas, iluminación y colgaduras. El reconocido artista Francisco Elías realizó la colosal estatua (medía unos dos metros y medio), de plomo dorado. Representaba al rey de cuerpo entero, con manto real y el cetro de mando en su mano derecha. La figura descansaba sobre un pedestal diseñado en 1824 por Francisco Bolarín (Figura 2). Los liberales destruyeron el monumento en 1837, en plena guerra carlista, y fundieron el plomo de la escultura para hacer balas. ${ }^{33}$ También en Murcia se erigió otra estatua a Fernando VII en 1828, esta de piedra, destruida asimismo por los liberales, ahora totalmente, una vez fallecido el monarca. ${ }^{34}$

Por similares vicisitudes pasó el monumento a Fernando VII levantado en Barcelona por iniciativa del conde de España para perpetuar el recuerdo de la visita del rey a la ciudad en 1827, durante su viaje para aplacar la rebelión de los agraviats. Fue el más ambicioso de los dedicados a este monarca, y según Carlos Reyero uno de los más importantes de su tiempo. Además, resultó ser el primero dedicado a un personaje histórico en Barcelona y la primera utilización del bronce en un monumento público en Cataluña. Su inauguración tuvo lugar en noviembre de 1831. La estatua, de notable mérito estético, fue ejecutada en París por el escultor Pierre-Joseph Chardigny. 35

La Gaceta de Madrid describió la obra de la siguiente forma: el rey es representado con corona rostral (esto es, de oro, al estilo de la antigua Roma), en actitud de pacificador, con uniforme militar, revestido con el manto de la Orden de Carlos III y con las condecoraciones reales, "la mano izquierda apoyada en el pomo de la espada, y el brazo derecho avanzado en ademán de imponer y mandar desaparecer a los siniestros y sangrientos genios de revolución y de discordia, restaurando la deseada paz..." La estatua descansaba sobre plinto de una pieza, colocado sobre un pedestal de mármol blanco de Carrara, cuyo zócalo era de jaspe amarillo de Tarragona. Todo ello estaba colocado sobre un basamento de tres gradas de jaspe amarillo y encarnado de Tolosa. Una balaustrada de jaspe

32 Carta del corregidor Rafael Garfias a varias autoridades locales (Murcia, 31 de enero de 1831), cit. por José Luis Melendreras Gimeno, La escultura en Murcia durante el siglo XIX, CAMUniversidad de Murcia, Murcia, 1997, p. 228.

33 José Luis Melendreras Gimeno, La escultura en Murcia durante el siglo XIX, op. cit., pp. 65-66. De este monumento solo queda un dibujo de Ramón Baquero. El pedestal fue utilizado como sustento de una estatua de Floridablanca inaugurada en 1849, que todavia se puede contemplar.

34 A. Baquero Almansa, Catálogo de los Profesores de las Bellas Artes Murcianas, Sucesores de Nogués, Murcia, 1913, p. 347.

35 Carlos Reyero, "La Fuente del Genio Catalán, Barcelona. Historia y significado politico", Locus Amoenus, 12, 2013-2014, pp. 157-176; del mismo autor: Monarquia y Romanticismo. El hechizo de la imagen regia, 1829-1873, Siglo XXI, Madrid, 2015, p. 204; Judit Subirachs i Burgaya, L'escultura del segle XIX a Catalunya. Del Romanticisme al Realisme, Abadia de Montserrat, Barcelona, 1994, p. 184. 
amarillo de las canteras de Tarragona circuía el conjunto, formando un corredor embaldosado con mármoles de Génova. La base era de jaspe azul y blanco de Rosas. Una verja formada con lanzas de hierro rodeaba el monumento. En medio del pedestal una inscripción, compuesta por el conde de España, en letras de bronce, decia: CONCORDIAE / FERDINANDUS VII/ HISP. ET IND. REGIO/ VERE AUGUSTUS/ P.P. ANNO MDCCCXXVII. ${ }^{36}$ La exaltación del monarca absoluto era evidente.

No menos relevante que el monumento resultaba su emplazamiento: el centro de la Plaza Palacio o Pla de Palau, en palabras de C. Reyero "el espacio público más amplio y con más edificios representativos de la Barcelona anterior a la Restauración", centro de poder emergente desde el siglo XVIII. ${ }^{37}$ En uno de sus lados se alzaba el Palacio Real, residencia de los antiguos virreyes y de Carlos IV cuando en 1802 visitó la ciudad con motivo del doble matrimonio de sus hijos Fernando (el futuro rey) y María Isabel con príncipes napolitanos. La Junta de Comercio había ideado levantar una columna para conmemorar la visita del Carlos IV, luego se pensó en un monumento a Lacy, y finalmente se colocó el de Fernando VII, sustituido a su vez, casi totalmente rehecho, por el dedicado al Genio Catalán.

El monumento fue destruido el 5 de agosto de 1835, durante el levantamiento popular en que fue asesinado el general Bassa. Después de arrastrar el cadáver del general, los congregados en la plaza se diseminaron por las calles de la ciudad e incendiaron diferentes edificios, en especial los dedicados a la recaudación de impuestos. ${ }^{38}$ La crónica de Panorama español refiere así lo acontecido a la estatua de Fernando VII: “...el grupo mayor y más considerable (del pueblo) se estaba empleando en derribar la estatua colosal de bronce de Fernando VII en actitud de mandar a los catalanes que se humillasen a sus pies. La verja de hierro que rodeaba el pedestal de esta estatua desapareció en un momento como si fuese de frágil caña, y con una cuerda atada al cuello cayó tirada por un gentío inmenso, rompiéndosele una mano. Un retrato de Isabel reemplazó a la estatua, que fue después recogida y vendida al extranjero, yendo a parar a París en casa de un fundidor de la calle de Anjou."39 (Figura 3)

36 Gaceta de Madrid del 26 de noviembre de 1831 (reproducida en Carlos Reyero, Monarquía y Romanticismo. El hechizo de la imagen regia, 1829-1873, op. cit., pp. 205-206)

37 Carlos Reyero, Monarquia y Romanticismo. El hechizo de la imagen regia, 1829-1873, op. cit., p. 158

38 Anna María García Rovira, La revolució liberal a Espanya i les clases populars, Eumo, Vic, 1989 , p. 346.

39 Panorama español. Crónica contemporánea, Panorama Español, Madrid, 1845, tomo III, p. 57. La noticia ofrecida por esta fuente sobre la fundición de la estatua contrasta con la idea generalizada de que tras la referida bullanga fue a parar a manos de la reina Gobernadora María Cristina. Esta la llevó durante su exilio parisino a su residencia de la Malmaison. Luego, cuando Napoleón III compró este palacio, regaló la estatua a la segunda hija de Fernando VII, Luisa Fernanda, quien en 1862 la colocó en el salón de columnas del palacio de San Telmo, en Sevilla. Más tarde, la estatua pasó a los jardines de este palacio y cuando estos fueron cedidos a la ciudad en 1893 la estatua fue trasladada a los jardines de La Torre de don Fadrique, junto al convento de Santa Clara, donde se conserva hoy mutilada. Con todo, tal vez esta no es la original: "Parece más lógico pensar, no obstante, que la pieza sevillana sea una réplica de la pieza que estuvo en Barcelona." (Carlos Reyero, Monarquía y Romanticismo. El hechizo de la imagen regia, 1829-1873, op. cit., p. 173). 
Una vez fallecido Fernando VII se impuso el deseo generalizado de borrar su memoria del espacio público, y también del privado. Han desaparecido muchos de los retratos del rey difundidos por doquier durante su vida, los cuales presidieron dependencias oficiales y mansiones particulares, y según José Luis Díez, los que nos han llegado se han salvado gracias a su calidad artística (o, añado, a cualesquiera razones de sus propietarios, laicos o eclesiásticos). ${ }^{40}$ Son excepción, entre los testimonios públicos de este tiempo, dos obras que han llegado hasta nuestros dias, ambas ubicadas en Madrid, en las que es explícita la referencia a este rey.

Una de ellas es la Puerta de Toledo, de agitada historia. Concebida como homenaje a la proclamación como rey de España de José I, se puso la primera piedra en 1813, acompañada de una arqueta con la Constitución de Bayona, medallas del rey José y otros papeles del momento. Ese mismo año, tras la salida de los franceses, el Ayuntamiento Constitucional de Madrid decidió proseguir su construcción, ahora en honor de Fernando VII, y sustituyó la caja por otra que contenía la Constitución de 1812 y medallas con la efigie de Fernando VII. En 1814, o poco después, se instaló una nueva arqueta con periódicos de la fecha, pero sin la Constitución. En 1820 se introdujo otra caja, con la Constitución de 1812, números de la Gaceta de Madrid alusivos a hechos señalados de la guerra contra los franceses y la instalación del sistema constitucional, medallas, nómina de los diputados a Cortes, etc. En 1824, tras el fin del constitucionalismo, se cambió la caja una vez más. En la nueva se metieron documentos relacionados con la recuperación por el rey de todo su poder, certificado de su matrimonio en 1819 con Maria Josefa Amalia de Sajonia, papeles sobre el congreso de Verona, Gacetas, medallas y un buen número de decretos y órdenes relativas al nuevo tiempo político. 41

La puerta de Toledo, símbolo de los cambios políticos, como cabe constatar, fue finalizada en 1827 (Figura 4). La coronan tres grupos escultóricos, obra de Ramón Barba y Valeriano Salvatierra, ninguno con la efigie del rey. En el central destaca una figura femenina (España), la cual recibe el vasallaje de las provincias y de las artes, representadas estas por sendas matronas. En el arco principal se colocó la siguiente inscripción (en latín en la cara exterior y en castellano en la interior): "A Fernando VII el Deseado, Padre de la Patria, restituido a sus pueblos, esterminada (sic) la usurpación francesa. El Ayuntamiento de Madrid consagró este monumento de fidelidad, de triunfo, de alegría. Año de 1827." Durante la revolución de 1854 el pueblo arrancó algunas letras y en la de 1868 todas las demás, quedando únicamente la fecha. ${ }^{42}$

40 José Luis Diez, "Nada sin Fernando. La exaltación del Rey Deseado en la pintura cortesana (1808-1823)", op. cit., p. 100.

41 Detalles sobre el contenidos de las arquetas en Luis Miguel Aparisi Laporta, "Alteraciones en la estatuaria madrileña durante el gobierno del rey intruso", Anuario del Instituto de Estudios Madrileños, $\mathrm{n}^{\circ}$ extra 1808 (2008), pp. 41-45. Vid. asimismo Ángel Fernández de los Ríos, Guía de Madrid. Manual del madrileño y del forastero, Madrid, La Ilustración Española y Americana, Madrid, 1876, pp. 206-208.

42 Ramón de Mesonero Romanos, Manual histórico-topográfico, administrativo y artístico de Madrid, Imp. de Antonio Yenes, Madrid, 1844 (edic. facsimilar, Ábaco, 1977), p. 415. La Puerta fue restaurada a finales del s. XX, recuperando la inscripción original. 
Carácter diferente, tanto por la naturaleza de la obra, como porque no ha sufrido alteración hasta nuestros días, es la representación alegórica de Fernando VII como protector de las artes, que figura en el friso sobre la columnata de la puerta de Velázquez (oeste) del Museo del Prado. Es obra de Manuel Barba y Manuel Hermoso, iniciada en 1829 y finalizada por Valeriano Salvatierra en 1842 (Figura 5). El rey está revestido de gran boato (sombrero de ricos plumajes, manto real, collar del Toisón), sin corona ni atributos militares. En palabras de Carlos Reyero, "se presenta como un rey magnánimo, a cuya corte acuden simbólicamente una sucesión de figuras clásicas, colocadas frente a él, a la izquierda [Arquitectura, Pintura y Escultura], mientras a la derecha quedan Minerva, Apolo, Mercurio y Neptuno." Es, en suma, la representación de una monarquía moderna. ${ }^{43}$

\section{EL REY EN CUBA}

Al igual que en la parte europea de la monarquía, tampoco han llegado hasta nuestros dias todos los monumentos y estatuas levantados en homenaje a Fernando VII en los territorios de Ultramar. Por ejemplo, en Aguascalientes (México), ha desaparecido la columna clásica, en cuya cima se colocó en 1808 una estatua de Fernando VII en piedra. Han quedado, sin embargo, dos muestras, ambas en Cuba, muy significativas por su cronología, pues fueron inauguradas al poco de fallecer el monarca. Ninguna permanece en el lugar para el que fuera concebida.

En la Plaza de Armas de Matanzas (hoy Parque de la Libertad) se plantó en 1836 una estatua del rey, de mármol de Carrara, ejecutada el año anterior por el escultor italiano Ignazio Peschiera (Figura 6). Mide dos metros de altura. El rey está coronado de laurel, vestido con manto real. A sus pies, alegorias de la conquista de América y del imperio que dominaba. Como casi todas las de Fernando VII, esta estatua sufrió varias mudanzas, según el signo político del tiempo. En 1869, tras la caída de los Borbones, fue colocada en una escalera del Palacio de Gobierno, en 1847 se le cambió de lugar, y en la actualidad está en un patio del Museo Provincial Palacio de Junco. ${ }^{44}$

La única estatua de Fernando VII que permanece en la actualidad en un espacio urbano abierto, aunque no exactamente el que le fuera asignado originariamente, es la de La Habana. Proyectada en 1827, no se inauguró hasta 1834, en acto solemne acompañado de grandes festejos, nota a destacar, pues ya habia fallecido el monarca. Se ubicó en la Plaza de Armas, centro político de la ciudad, frente al Palacio de los Capitanes Generales.

El propio Fernando VII eligió el dibujo que sirvió de modelo, ejecutado en yeso por José Álvarez Bouquel. Al morir este, se encargó del proyecto hasta su finalización el escultor Antonio Solà. El rey aparece de cuerpo entero, con el cetro de mando en la mano derecha, vestido simbólicamente con el traje de la Orden

43 Carlos Reyero, Monarquía y Romanticismo. El hechizo de la imagen regia, 1829-1873, op. cit., pp. 207-208.

44 Rodrigo Gutiérrez Viñuales, Monumento conmemorativo y espacio público en Iberoamérica, Cátedra, Madrid, 2004, pp. 174-175. 
Americana de Isabel La Católica, instituida por Fernando VII en 1815 para premiar la lealtad y los méritos en favor de la prosperidad de aquellos territorios. A eso hacen referencian la inscripción al pie de la estatua y la que figuraba en la verja que la circundaba. La primera rezaba: "Ferdinandus VII Rex/ Habanensi Populo/ Desiderio Fidelitate Clarissimo/ Imagine Corde Pepetuo Adesse Voluit. MDCCCXXXIII." ("El Rey Fernando VII a su pueblo de la Habana, insigne por su amor y fidelidad, quiso estar presente en imagen como lo está siempre en su corazón, 1833") La colocada en los paños de la verja: "La siempre fiel Ciudad de La Habana al rey Fernando VII".

La presencia del rey en el principal territorio ultramarino sobre el que aún ejercía autoridad al final de su reinado, y la expresión de fidelidad de los habaneros, agradecidos por los beneficios económicos dispensados a la isla por el monarca, fueron los motivos que impulsaron a Claudio Martínez de Pinillos, superintendente general del Ejército y Hacienda de Cuba, y desde 1833 conde de Villanueva, a emprender el monumento. Así lo expresó en carta dirigida al monarca para recabar su permiso: "La erección de un Consulado nivelado bajo las reglas de las sabias ordenanzas de Bilbao; diversos establecimientos científicos, agronómicos y políticos, debidos a la Real Munificencia (...); el activo fomento y gracias dispensadas a su población blanca con el objeto de asegurar su estabilidad y desvanecer el peligro común a las Antillas (...); franquicias de todas clases, muchas de ellas arrancadas en ingeniosa lucha durante el ilegal sistema constitucional, tales son, entre otros innumerables beneficios los títulos de protección paternal que tiene del Rey Ntro. Sr. esta preciosa parte de sus dominios. Pero todos ellos juntos no pesan en la balanza política tanto como uno Solo (sic) de que se reconoce deudora a la ilustrada piedad de su soberano: este es el goce y ejercicio de su libre comercio..."45

La estatua de Fernando VII era, en suma, expresión del reconocimiento de la élite habanera a un rey del que recibió no pocos favores y al que se le relacionó con el desarrollo económico de la isla a principios del s. XIX. ${ }^{46}$ Esto explica que, como en el caso de la instalada en Matanzas, fuera inaugurada después del fallecimiento del rey, y es la razón de su permanencia. Los cubanos que se sintieron favorecidos por el régimen colonial defendieron con calor el mantenimiento de la estatua en su emplazamiento original, incluso después de la independencia de la isla y la proclamación de la República. En 1916 lo explicó Eugenio Sánchez de Fuentes y Peláez en su libro Cuba monumental: "este mármol monárquico perdura hasta nuestros dias, sin sentirse nadie molesto..., pues

45 Cit. por Ángel Carcines, "La estatua habanera de Fernando VII. Ascenso y caida de un rey", Opus Habana, $\mathrm{n}^{\circ}$ 52, 2013. Vid. asimismo Anna Riera, "Antoni Solà (1780-1861), una vida dedicada a l'art”, en VV.AA., La bellesa ideal. Antoni Solà (1780-1861), escultor a Roma, Ajuntament de Barcelona, Barcelona, 2009.

46 El promotor del monumento, el conde de Villanueva, ferviente fernandino, además de en su función recaudadora en favor de la metrópoli, se mostró muy activo en el impulso del desarrollo económico de La Habana. Entre otras realizaciones, a él se debió la construcción de un acueducto, llamado de Fernando VII (1835), obras de embellecimiento de la ciudad, y la construcción del primer ferrocarril español (La Habana-Güines, 1837). Su gestión fue muy aplaudida por la élite cubana. 
todos saben también, en los pasados tiempos, la influencia de este Rey fue verdaderamente beneficiosa..." 47

Tras una larga polémica, especialmente viva en los años cuarenta del siglo $\mathrm{XX}$, en la que el conservador Diario de la Marina se manifestó por mantener en su sitio la estatua, y el historiador de la ciudad de La Habana Emilio Roig de Leuchsenring por eliminarla, se acordó su retirada en 1955. En su lugar se erigió otra de Carlos Manuel de Céspedes, padre de la patria cubana. La efigie de Fernando VII no ha sido destruida. Se colocó en el Museo de la ciudad (Palacio de los Capitanes Generales) y en 1975 volvió a emplazarse en el espacio público, en la calle O'Reilly, una de las que dan a la Plaza de Armas. El historiador de la ciudad de La Habana, Eusebio Leal, puso una larga inscripción alusiva al monarca representado, que comienza con esta frase: "Su reinado fue ejemplo de desvergüenza y absolutismo." 48

\section{CONSIDERACIÓN FINAL}

Tras el fallecimiento de Fernando VII se procedió de manera generalizada a borrar su memoria. Por supuesto, no se proyectó ningún monumento en su honor, y se destruyeron casi todos los existentes, algunos con indisimulada saña. Los únicos levantados en los años inmediatamente posteriores (en La Habana, en 1834, y en Matanzas, en 1836), habían sido concebidos en vida del rey. Su inauguración y permanencia en el tiempo se explican por las circunstancias específicas de Cuba, cuya élite económica se consideró favorecida por la política de este monarca. Todo lo contrario sucedió en España, donde el ataque al rey podríamos calificarlo de total, lo cual, si seguimos esta lógica, equivaldría a decir que en esta parte la percepción general sobre el reinado era funesta. La permanencia hasta nuestros días de tres monumentos en su honor en Madrid ("La Fuentecilla" del barrio de La Latina, la Puerta de Toledo y el friso de la puerta de Velázquez en el Museo del Prado) no guarda relación con el deseo de perpetuar su memoria. Es probable que su continuidad se deba fundamentalmente a que en ellos no se muestra su imagen, con la excepción del friso del Museo del Prado, pero en este caso pasa casi desapercibida y no todos identificarán la figura central con Fernando VII. Podriamos afirmar, en consecuencia, que en España hubo necesidad de destruir el recuerdo de este rey para construir la memoria de la nación liberal, esto es, lo opuesto a lo que él significó.

Como he defendido en otro lugar, Fernando VII tuvo un concepto superlativo de su dignidad y de su persona, de ahí su obsesión por realzarse a sí mismo y por imponer su presencia y autoridad a sus súbditos. Por otra parte, entendió perfectamente que su acceso al trono en 1808, en vida de su padre, y su permanencia a partir de 1814, se debieron en buena medida a la imagen positiva que de él se habían forjado los españoles. Percibió que ante todo era un rey imaginado. Por eso resultaba fundamental alimentar su imagen. Era la forma de garantizar su pleno poder en el presente y dejar el mejor recuerdo a la posteridad.

47 Cit. por Ángel Carcines, "La estatua habanera de Fernando VII. Ascenso y caída de un rey", op. cit.

48 Sobre la polémica en Cuba en torno a la estatua de Fernando VII, vid. María Grant, La estatua habanera de Fernando VII. En favor del Patrimonio de la Cubanidad", Opus Habana, ${ }^{\circ}$ 52, 2013. 
Para ello recurrió a los medios disponibles en la época, entre los cuales ocupaban un lugar sobresaliente las artes plásticas. No sorprende, en consecuencia, que vigilara personalmente los bocetos de sus estatuas y que ordenara las inscripciones de los monumentos levantados en su honor. Tampoco extraña, conocida su meticulosidad en la vida diaria, que se ocupara de recoger y seleccionar personalmente aquellos papeles que consideró más relevantes para transmitir a la posteridad la mejor impresión sobre sí mismo, su familia y su reinado (esta documentación forma en la actualidad el fondo denominado "Papeles Reservados de Fernando VII", una parte conservada en el Archivo General de Palacio y otra en el del Congreso de los Diputados).

No sería aventurado suponer que si no se erigieron en su honor más monumentos públicos que los conocidos, y que algunos de los proyectados no llegaran a ejecutarse, no fue por falta de voluntad del rey, impulsor él mismo de varios de ellos, o de la mayoría, sino por falta de recursos económicos. En lo relacionado con su proyección personal, Fernando VII fue un rey moderno. Entendió que el tiempo de la política, en el que el constitucionalismo es asunto central, exigía procedimientos nuevos para sustentar la monarquía deseada por él, que no era la constitucional, sino una forma despótica, yo diría tiránica, diferente no solo del modelo constitucional, sino también del imperante durante el Antiguo Régimen. Como en tantos otros aspectos de su vida y de su reinado, la contradicción fue nota esencial en este monarca, al que por varias razones podemos calificar de singular.

\section{ILUSTRACIONES}

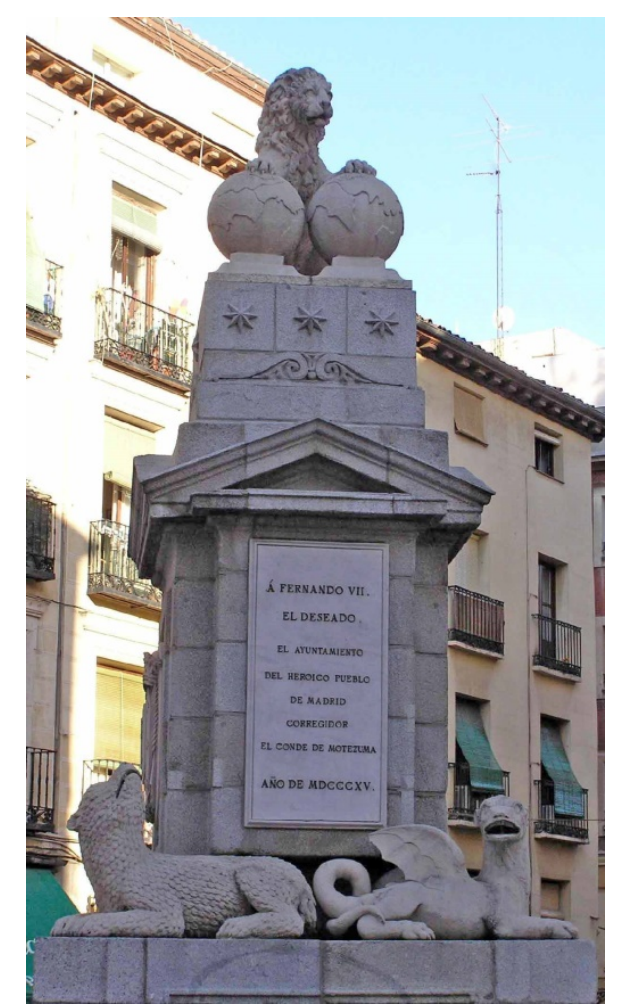

Figura 1. Monumento en el barrio de La Latina ("La Fuentecilla") (Madrid) 


\section{Emilio La Parra López}

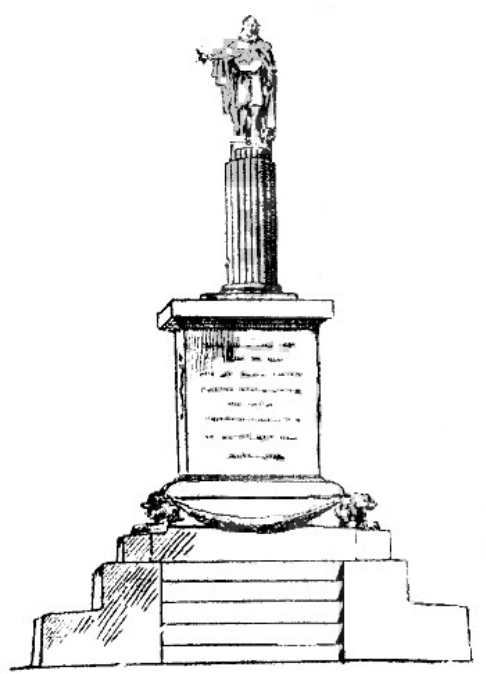

Fig. 2. Dibujo de Baquero de la estatua de Fernando VII en la Glorieta de Murcia

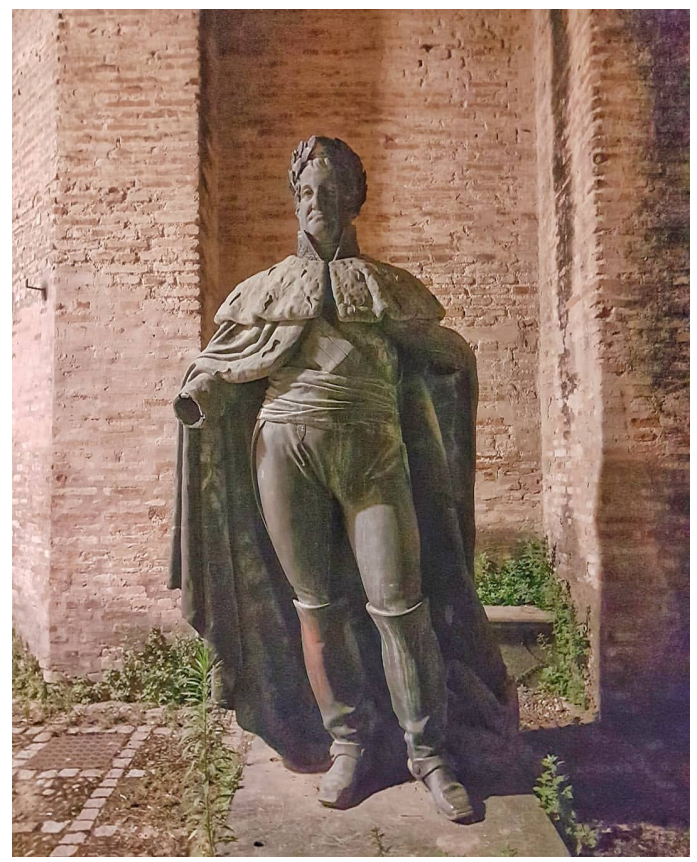

Fig. 3. Posible copia de la estatua de Fernando VII del monumento levantado en la Plaza de Palacio en Barcelona, por P.-J. Chardigny. Museo de Santa Clara (Sevilla)

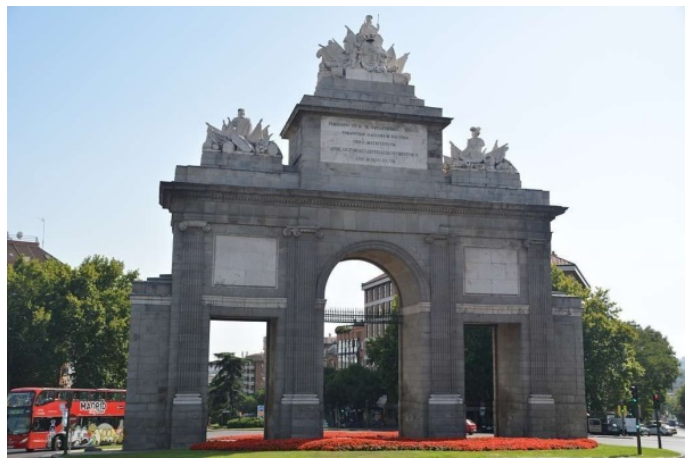

Fig. 4. Puerta de Toledo (Madrid) 


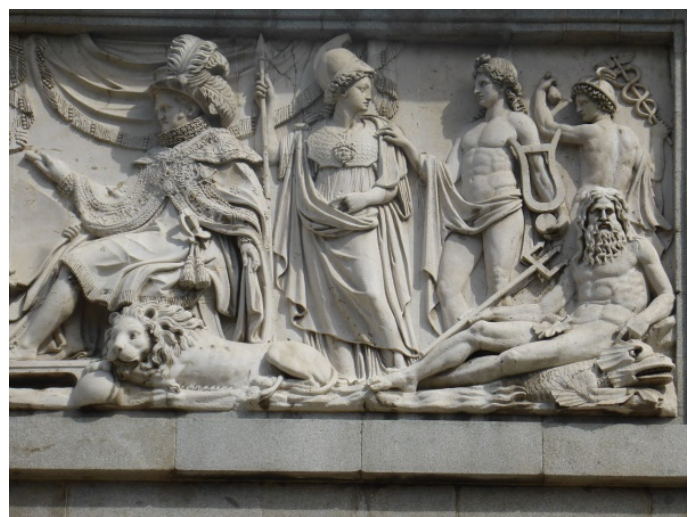

Fig. 5. Detalle del friso de la puerta de Velázquez, Museo del Prado

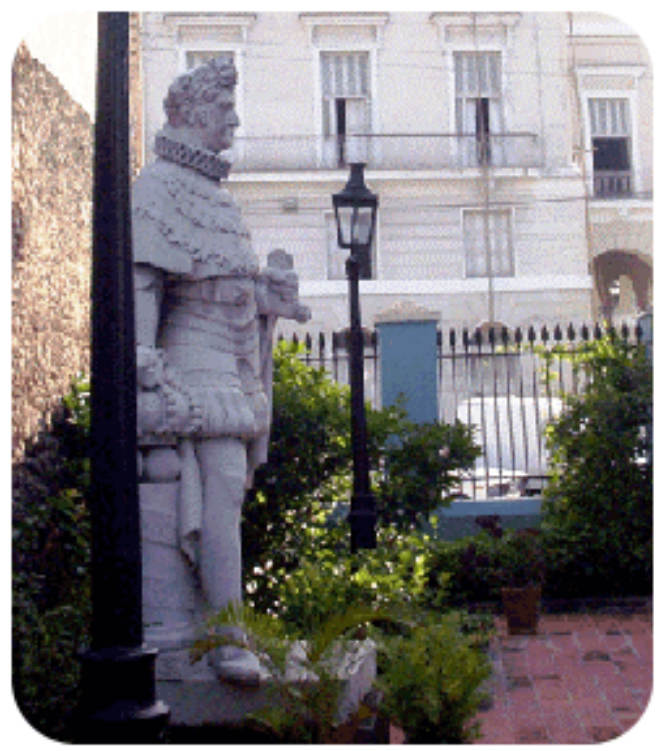

Fig. 6. Fernando VII, por I. Peschiera. Museo Palacio de Junco, Matanzas (Cuba)

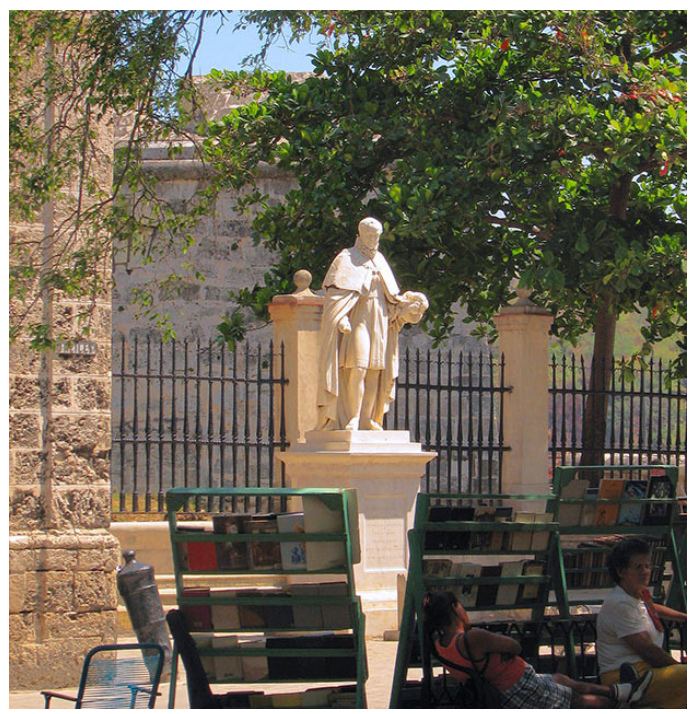

Fig. 7. Estatua de Fernando VII, calle O’Reilly, La Habana

Fecha de envio / Submission date: 12/04/2019

Fecha de aceptación / Acceptance date: 8/05/2019 